\title{
A inserção de equipes de saúde bucal no Programa Saúde da Família no Estado de Minas Gerais
}

\author{
The insertion of oral health services \\ in the Family H ealth Program at M inas Gerais State, Brazil
}

Eloisio do Carmo Lourenço ${ }^{1}$

Ana Cláudia Baladelli Silva ${ }^{1}$

$M$ arcelo de Castro $M$ eneghin ${ }^{2}$

Antonio Carlos Pereira ${ }^{2}$

${ }^{1}$ Departamento de OdontologiaSocial, FaculdadedeOdontologia dePiracicaba, UNICAMP.

Av. Limeira 901 Caixa

Postal 52. 13414-903

Piracicaba SP.

eloisio@matrix.com.br

${ }^{2}$ Departamento de

Odontologia Social,

FaculdadedeOdontologia

dePiracicaba,

Universidade Estadual de

Campinas.
Abstract The objective of this study was to analyze the administrative and operational aspects of O ral Health Teams $(\mathrm{OHT})$ at the Family Health Program (FHP) in M inas Gerais State, Brazil. Two types of questionnaire were sent to 310 cities, and $53.5 \%$ were answered until June/2004. From the total of the respondents, $66.9 \%$ reported unstable forms of hiring and $82.5 \%$ of the dental surgeons receivewage 9 times lower than minimum wage for full-time job ( 8 hours); $75.9 \%$ of the cities presented an average of 4000 inhabitants for OHT. In average, $79.6 \%$ of all OHTs attended all ages group; $48.9 \%$ of dental surgeons reported not having participated in any of the courses offered. The integration between $\mathrm{OH}$ and FH P teams could be seen in $76.2 \%$, however only $54 \%$ organize regular meetings. The positive points observed werethat FH P teamsfollow the principle of universality, the eight-hour shift and the quantitative extension allowing a higher access to oral health services. As negative points, it was observed the lack of qualification of the $\mathrm{OHT}$, the excessive demand, the precarious work relations and the lack of involvement between $\mathrm{OH}$ and $\mathrm{FH}$ teams. Key words Oral health team, Family Health Program, Universality
Resumo 0 objetivo deste estudo foi analisar aspectos administrativos e operacionais das Equipes de Saúde Bucal (ESB) no Programa Saúde da Família (PSF) no Estado de M inas Gerais. Foram encaminhados a 310 municípios dois tipos de questionários, dos quais $53,5 \%$ retornaram os questionários até o final do primeiro semestre de 2004. D estes respondentes, $66,9 \%$ relataram formas de contratação instáveis, com $82,5 \%$ dos cirurgi ões dentistas recebendo salário abaixo de nove salários mínimos por oito horas diárias de trabalho; $75,9 \%$ dos municípios relataram uma proporção de até 4.000 habitantes por ESB e $74,1 \%$ utilizavam mais de uma forma de agendamento dos usuários. Em média, $79,6 \%$ das ESB atendiam todas as faixas etárias; $48,9 \%$ dos cirurgiões dentistas relataram não ter participado de nenhum curso de capacitação. A integração entre ESB e Equipes de Saúde da Família (ESF) foi verificada em $76,2 \%$; todavia, apenas $54 \%$ realizam reuniões frequentes. Como pontos positivos, observou -se o princípio da universalidade, a jornada de trabalho de oito horas e a ampliação quantitativa, possibilitando maior acesso aos serviços de saúde bucal e, como pontos negativos, a falta decapacitação das ESB, a demanda excessiva, a precarização das relações detrabal ho e a falta deenvolvimento entre ESB e ESF.

Palavras-chave Equipe de saúde bucal, Programa Saúde da Família, U niversalidade 


\section{Introdução}

A introdução do Sistema Ú nico deSaúde(SUS) na Constituição de 1988, regulamentado posteriormente pelas leis 8.080 e 8.142 de 1990, determinou grandes mudanças nas políticas de saúde no Brasil. $O$ reconhecimento da crise do model o assistencial predominante, no âmbito da saúde coletiva, vem suscitando a emergência de propostas que visem à transformação do sistema de atenção em saúde, de suas práticas e, em articulação com estas, do processo de trabalho em saúde 1 . Dentro destas propostas de mudança, surge o Programa Saúde da Família (PSF), definido pelo M inistério da Saúde (MS) como uma estratégia que prioriza as ações de promoção, proteção e recuperação da saúde dos indi víduos e da família, do recém-nascido ao idoso, sadios ou doentes, de forma integral e contínua? .

A primeira etapa de sua implantação se iniciou em 1991 por meio do Programa de Agentes Comunitários de Saúde (PACS), o qual tinha como unidade de ação a família. Este programa apresentou bons resultados, particularmente na redução dos índices de mortalidade infantil. A partir de 1994, iniciou-se a formação das primeiras equipes do Programa Saúde da Família, incorporando e ampliando a atuação dos Agentes Comunitários de Saúde (ACS)².

Os resultados de uma Pesquisa Nacional por Amostra de Domicílio (PNAD) de 1998, realizada pelo Instituto Brasileiro de Geografia e Estatística (IBGE), demonstraram que, atéentão, 29,6 milhões de brasileiros nunca tinham ido ao cirurgião-dentista. N este contexto, em função da necessidade de aumentar as ações de prevenção e garantir os investimentos na área curativa em procedimentos odontológicos, o Ministério da Saúde (MS) propôs como estratégia de reorganização da atenção básica à saúde, a inclusão de Equipes de Saúde Bucal (ESB) no Programa Saúde da Família.

A inclusão deESB no PSF teve a sua concretização através da Portaria 1.444/GM de 2000, na qual o M S determinou o incentivo financeiro às Equipes de Saúde Bucal no PSF. Foram definidas duas modalidades de equipes, sendo a modalidade I composta de um cirurgião-dentista (CD) e um atendentedeconsultório dentário (ACD) ea modalidade II de um cirurgião-dentista, um atendente de consultório dentário eum técnico em higiene dental (THD). Os objetivos foram diminuir os índices epidemiológicos de saúde bucal e ampliar o acesso da população Brasileira às ações de saúde bucal ${ }^{3}$.

Em março de 2004, o M S lança o "Brasil Sorridente", política de saúde bucal do Governo Fede- ral, com o objetivo de ampliar 0 atendimento e melhorar as condições de saúde bucal da população brasileira. Cinco frentes de ação foram estabelecidas: ampliação do atendimento na rede básica, criação de centros deespecialidades, ações educativas, implantação de próteses e fluoretação das águas. Para ampliar 0 acesso à rede básica, houve um aumento nos incentivos financeiros das ESB no PSF, com investimentos iniciais na ordem deR \$ 18,9 milhões, resultando em um crescimento de $106 \%$ das ESB no PSF entre dezembro de 2002 e setembro de $2004^{4}$.

Vários autores ${ }^{1,5-8}$ têm questionado as formas de implantação do PSF e da inclusão das ESB no Brasil. São levantadas questões em relação às diferenças nas realidades locais, capacidade de atendimento, recursos humanos, financiamentos, etc. No que tange às ESB, como a implantação se deu tardiamente, há que se considerar dificuldades na integração dos profissionais de saúde bucal às equipes do PSF, bem como diferenças nas formas de implantação das ESB.

Segundo a Secretaria de Estado da Saúde de M inas Gerais ${ }^{9}$ (SES-M G), o Programa de Saúde da Família (PSF) éuma estratégia e parteintegrante e fundamental do SUS, o qual vem avançando não uniformemente em todos os municípios com diversos desafios e dificuldades, tais como financiamento, modalidades de contratação, carência de profissionais, capacitação do pessoal, manutenção de quadros, execução financeira e outras. Calado ${ }^{10}$, Goulart ${ }^{11}$ e Baldani ${ }^{1}$ abordaram tais aspectos e comprovaram as dificuldades levantadas em diferentes regiões do país. Assim, torna-se importante a identificação e análise das situações de implantação edo desenvolvimento das ações das ESB no PSF, buscando semprea eficácia e eficiência dos serviços ofertados a população.

Buscou-se neste artigo identificar e analisar aspectos administrativos e operacionais das Equipes de Saúde Bucal no Programa Saúde da Família em municípios do Estado de M inas Gerais.

\section{M aterial e método}

Este trabalho foi submetido e aprovado pelo Comitê de Ética em Pesquisa (CEP) da FOP/UNICAM P sob o protocolo CEP n‥ 082/2004.

\section{Amostra}

O Estado de M inas Gerais possui 853 municípios, dos quais $723(84,7 \%)$ implantaram o Programa Saúde da Família. Destes, segundo dados 
da SES-M G, 310 municípios (36,3\%) haviam incorporado ESB no PSF até o primeiro semestre de 2004, num total de 724 equipes, sendo $573(79,1 \%)$ na modalidade I e $151(20,9 \%)$ na modalidade II.

Este estudo abrangeu todos os 310 municípios que apresentavam Equipes de Saúde Bucal no Programa Saúde da Família até o primeiro semestre de 2004 , sendo que $62 \%$ eram de pequeno porte (até10.000 habitantes), 33\% demédio porte ( 10.000 a 50.000 habitantes) e $5 \%$ de grande porte (acima de 50.000 habitantes).

Dezoito municípios informaram que não estavam em condições de encaminhar respostas, sendo que quinzemunicípios, com um total dezessete equipes, al egaram motivos políticos devido às eleições municipais (ocorreram demissão de secretários de saúde, de coordenadores, dissolução de equipes, férias coletivas para todos do PSF, cancelamento de contratos, etc.); dois municípios, com duas equipes cada, informaram que não possuíam mais ESB no PSF e um município, com 174 equipes, não aceitou o certificado do CEP desta pesquisa, por possuir um CEP na própria Secretaria Municipal de Saúde.

Em relação aos municípios, 53,5\% (166) retornaram os questionários. 0 porcentual deESB respondentes correspondeu a 38,4\% (278) do total; $76,6 \%$ destas (213) eram modalidadel e23,4\% (65), modalidade II. Os resultados deste estudo podem ser considerados representativos do estado devido aos municípios respondentes apresentarem as seguintes características: a) manutenção da proporcionalidade em relação ao porte demográfico dos municípios; b) pela distribuição geográfica no estado; c) pela representatividade por DADS (Diretorias de Ações Descentralizadas de Saúde), onde de um total de 28 DADS do estado, 26 estiveram envolvidas na pesquisa e 25 tiveram representação; d) pela manutenção da proporcionalidade entre as equipes modalidade I e II em relação ao estado; e) justifica-se a porcentagem de ESB respondentes pelo fato do município com 174 ESB não responder à pesquisa, sendo que, se excluíssemos este município da amostra, o porcentual de ESB respondentes seria de $50,5 \%$. Além disso, foi realizado um cálculo do erro amostral, levando-se em consideração uma taxa de resposta de $50 \%$, um nível deconfiança de $95 \%$ eum N (mínimo) de 166 , chegando a um erro amostral de 5,9\%.

\section{M etodologia}

0 estudo proposto é de natureza quantitativa e qualitativa econstou do envio de doistipos deques- tionários, previamente testados (fase piloto), aos municípios, com questões objetivas (fechadas) e uma questão subjetiva (aberta), abordando aspectos administrativos e operacionais das ESB no PSF.

Um dos questionários abordava aspectos administrativos das ESB no PSF, sendo destinado aos coordenadores de saúde bucal ou, não havendo este cargo, aos secretários de saúde dos municípios que apresentavam ESB no PSF, contendo questões relativas a: a) início da implantação das ESB; b) número de ESB no município; c) população coberta pelas ESB; d) localização das ESB; e) forma de contratação dos cirurgiões dentistas das ESB; f) jornada de trabalho dos profissionais da ESB; g) faixa salarial dos profissionais (cirurgião-dentista, ACD e THD) que atuam no programa; $h$ ) recursos destinados às ESB. $O$ segundo questionário abordava aspectos operacionais das ESB e foi encaminhado aos cirurgiões-dentistas que atuavam nas ESB do PSF e buscava informações relativas a: a) tempo de contratação do cirurgião-dentista no PSF ; b) participação em cursos de capacitação; c) tipo de clientela atendida pela ESB; d) organização da demanda; e) frequência de visitas domiciliares pelo cirurgião-dentista; f) referência e contra-referência em saúde bucal; g) ações desempenhadas pelo cirurgião-dentista e pessoal auxili$\mathrm{ar} ; \mathrm{h}$ ) integração entre aESB e o restante da equipe de saúde da família. A questão subjetiva (aberta) solicitava que fossem relatadas experiências, inovações, dificuldades ou mudanças observadas em relação às ESB no PSF.

Os questionários foram encaminhados aos municípios através das DADS, sendo que cada município recebeu um envelope contendo o questionário destinado ao coordenador de saúde bucal ou secretário de saúde, o questionário destinado ao CD em número correspondente ao deESB implantadas e os termos de consentimento livre e esclarecido (TCLE). Juntamente com os questionários, foram encaminhados envelopes/resposta devidamenteseladose endereçados aos pesquisadores para que fossem feitas as devoluções. Facultou-se aos municípios a oportunidade de responder a pesquisa por fax ou pela internet, sendo disponibilizada uma senha de acesso a um site desenvolvido especificamente para este fim com endereço eletrônico htpp://www.pesquisaonline.sserver.com.br.

Os dados foram submetidos à análise estatística descritiva. 0 testeestatístico qui-quadrado $\left(\chi^{2}\right)$ foi aplicado para verificar a associação entreo porte municipal ea implantação de ESB no PSF no Estado de M inas Gerais. 
Resultados

A associação entre o porte municipal ea implantação das ESB no PSF no Estado de M inas Gerais foi estatisticamente significante $(p<0,01)$, demonstrando que o porte municipal pode ter influenciado na implantação das ESB no PSF.

Os questionários respondidos pelos coordenadores de saúde bucal ou secretários de saúde dos municípios demonstraram que, em relação ao número de ESB implantadas por município, a maior parte $(57,2 \%)$ implantou apenas uma equipe, $21,7 \%$, duas equipes, $7,2 \%$ dosmunicípiosapresentavam três equipes e $13,9 \%$, mais de três ESB no PSF (Tabela 1). Quanto à cobertura populacional, $54,8 \%$ dos municípios responderam que as ESB eram responsáveis pelo atendimento de até três mil pessoas, $21,1 \%$ atendiam cerca de quatro mil pessoas, $10,2 \%$, de cinco a seis mil e $13,9 \%$ das ESB atendiam mais de seis mil pessoas (Tabela 1). Em relação à localização das USF com ESB, 53\% (88) estavam localizadas na região urbana, 6\% (10), em região rural, 39,1\% (65) com ESB urbana e rural e 1,8\% (3) em outros locais. Quanto à forma de contratação dos profissionais das ESB, $21 \%$ relataram teste seletivo interno, $12 \%$, concurso externo, $16,3 \%$, credenciamento e $50,6 \%$ relataram outras formas como contrato, indicação política, nomeação, licitação, terceirização, contratos por cooperativas, contrato temporário, contrato de prestação de serviços, etc. (Tabela 1).

Tabela 1. Aspectos administrativos das ESB no PSF no Estado de M inas Gerais, 2004.

\begin{tabular}{lrc}
\hline Aspectos administrativos & $\mathrm{n}$ & $\%$ \\
\hline Formas de seleção e contratação & & \\
Concurso externo & 20 & 12,0 \\
Teste seletivo interno & 35 & 21,0 \\
Credenciamento & 27 & 16,3 \\
Outras formas de contratação & 84 & 50,6 \\
Total & 166 & 100 \\
Cobertura populacional & & \\
Três mil pessoas & 91 & 54,8 \\
Quatro mil pessoas & 35 & 21,1 \\
Cinco a seis mil pessoas & 17 & 10,2 \\
Mais de seis mil pessoas & 23 & 13,9 \\
Total & 166 & 100 \\
Número de ESB implantadas por município & & \\
Uma equipe & 95 & 57,2 \\
Duas equipes & 36 & 21,7 \\
Três equipes & 12 & 07,2 \\
Mais de três equipes & 23 & 13,9 \\
Total & 166 & 100 \\
\hline
\end{tabular}

Em relação à jornada de trabalho, 93,3\% (155) dos municípios relataram oito horas diárias ( 40 horas semanais), sendo que, para cumprir esta jornada, 10,2\% dos cirurgiões-dentistas tinham remuneração abaixo decinco salários mínimos ( $R \$$ $1.200,00$ ) (valor referência SM $=R \$ 240,00$ ), $50 \%$ recebiam entre 5 e 7,5 salários mínimos ( $R$ \$ $1.200,00$ a R $\$ 1.800,00), 22,3 \%$, entre 7,5 e 9 salários mínimos ( $R \$ 1.801,00$ a $R \$ 2.200,00$ ) e $17,4 \%$ dos cirurgiões-dentistas recebiam um salário acima de nove salários mínimos (acima de R\$ 2.201,00), enquanto dentro da categoria de técnico em higiene dental (THD), 12,3\% têm salário abai$x$ o de $R \$ 300,00,58,5 \%$, entre $R \$ 301,00$ e $R \$ 600,00$, $6,1 \%$ recebiam um salário entre $R \$ 601,00$ e $R \$$ $1.000,00$ e 23\% dos THD tinham salário acima de $R \$ 1.000,00$, enquanto $4,2 \%$ dos atendentes de consultório dentário (ACD) tinham salário abaixo de $R \$ 250,00,86,7 \%$, entre $R \$ 251,00$ e $R \$ 400,00,9 \%$ recebiam salário entre $R \$ 401,00$ e $R \$ 550,00$ (Tabela 2).

Quanto ao financiamento, 83,1\% (138) dos municípios afirmaram destinar a totalidade do incentivo financeiro das ESB para a odontologia e $86,1 \%$ (143) dos municípios não receberam nenhum recurso extra para as ESB no PSF. 98,2\% (163) dos municípios afirmaram ser importante para a população a inclusão de ESB no PSF, enquanto $2 \%$ afirmaram que estes recursos deveriam ser canalizados para outras ações prioritárias de saúde.

Tabela 2. Salários dos componentes das ESB no PSF no Estado de Minas Gerais, em 2004* .

\begin{tabular}{|c|c|c|}
\hline Salários da ESB em R\$ & $\mathrm{N}$ & $\%$ \\
\hline \multicolumn{3}{|l|}{ Dentistas } \\
\hline Abaixo de $1.200,00$ & 17 & 10,2 \\
\hline Entre $1.200,00$ e $1.800,00$ & 83 & 50,0 \\
\hline Entre $1.801,00$ e $2.200,00$ & 37 & 22,3 \\
\hline Acima de $2.201,00$ & 29 & 17,4 \\
\hline Total & 166 & 100 \\
\hline \multicolumn{3}{|l|}{ THD } \\
\hline Abaixo de 300,00 & 8 & 12,3 \\
\hline Entre 301,00 e 600,00 & 38 & 58,5 \\
\hline Entre 601,00 e $1.000,00$ & 4 & 06,1 \\
\hline Acima de $1.000,00$ & 15 & 23,0 \\
\hline Total & 65 & 100 \\
\hline \multicolumn{3}{|l|}{$A C D$} \\
\hline Abaixo de 250,00 & 007 & 04,2 \\
\hline Entre 251,00 e 400,00 & 144 & 86,7 \\
\hline Acima de $R \$ 401,00$ e $R \$ 550,00$ & 015 & 09,0 \\
\hline Total & 166 & 100 \\
\hline
\end{tabular}


Em relação aos aspectos operacionais, os questionários respondidos pelos 278 cirurgiões-dentistas das ESB apontavam que 42,1\% (117) destes trabal havam no PSF há menos de um ano, 32\% (89), entre um e dois anos, $15,8 \%$ (44) estavam contratados há pelo menos três anos e 10,1\% (28), há mais de três anos. Quanto à capacitação, 51,1\% (142) dos cirurgiões-dentistas afirmaram ter participado depelo menos um curso sobrePSF, enquanto $48,9 \%$ (136) nunca participaram (Tabela 3).

Em relação à clientela atendida, 88,8\% das equipes atendiam pré-escolares, $88,1 \%$ atendiam escolares, $86 \%$, adultos, $83,8 \%$ atendiam adolescentes, cerca de $76,9 \%$ dos cirurgiões-dentistas afirmaram atender a gestantes, $76,6 \%$ atendiam idosos, enquanto apenas $56,1 \%$ atendiam bebês de zero a três anos.

Ao analisar a organização da demanda, observa- seque $206 \operatorname{ESB}(74,1 \%)$ relataram utilizar mais de uma forma de agendamento dos usuários, sendo $51,1 \%$ nas USF pelo ACD, $43,9 \%$ através do Agente Comunitário de Saúde (ACS), cerca de

Tabela 3. Aspectos operacionais das ESB no PSF no Estado de M inas Gerais, 2004.

\begin{tabular}{|c|c|c|}
\hline Aspectos operacionais & $\mathrm{n}$ & $\%$ \\
\hline \multicolumn{3}{|c|}{ Periodicidade das reuniões entre ESB e ESF } \\
\hline Semanal & 47 & 16,9 \\
\hline Quinzenal & 28 & 10,1 \\
\hline M ensal & 75 & 27,0 \\
\hline Esporádicas & 97 & 34,9 \\
\hline Nunca & 31 & 11,2 \\
\hline Total & 278 & 100 \\
\hline \multicolumn{3}{|l|}{$\begin{array}{l}\text { Encaminhamento dos casos de maior } \\
\text { complexidade }\end{array}$} \\
\hline Município vizinho & 133 & 47,7 \\
\hline Próprio município & 78 & 28,0 \\
\hline Outros & 36 & 13,3 \\
\hline Própria USF & 17 & 06,1 \\
\hline Não resolvidos & 14 & 05,0 \\
\hline Total & 278 & 100 \\
\hline \multicolumn{3}{|l|}{ Periodicidade das visitas domiciliares } \\
\hline Semanalmente & 47 & 16,9 \\
\hline Quinzenalmente & 20 & 07,2 \\
\hline Bimestralmente & 36 & 12,9 \\
\hline Sempre que necessário & 133 & 47,8 \\
\hline Nunca & 42 & 15,1 \\
\hline Total & 278 & 100 \\
\hline \multicolumn{3}{|c|}{ Participação dos CD em cursos de capacitação } \\
\hline Sim & 142 & 51,1 \\
\hline Não & 136 & 48,9 \\
\hline Total & 278 & 100 \\
\hline
\end{tabular}

$39,9 \%$ por livre demanda como porta de entrada, $26,9 \%$ triagem de risco, enquanto $12,9 \%$ das ESB relataram outras formas de agendamento (por exemplo, levantamentos em escolas) e 9\% realizavam agendamento na USF através do THD (Tabela 4). Em relação às visitas domiciliares executadas pelos $C D$ s, $47,8 \%$ destes responderam que as faziam sempre que necessário, 16,9\%, semanalmente, $7,2 \%$ dos cirurgiões-dentistas as realizavam quinzenalmente, $12,9 \%$, a cada dois meses, e $15,1 \%$ dos cirurgiões-dentistas nunca as realizavam por falta de tempo (Tabela 3). Em relação aos casos clínicos de maior complexidade, foi identificado que aproximadamente $28 \%$ eram resolvidos no próprio município, 47,7\% eram encaminhados para centros de referência em municípios maiores e próximos, $6,1 \%$ dos casos não eram encaminhados, contudo, resolvidos na própria unidade, $5 \%$ não eram resolvidos e $13,3 \%$ recebiam outros encaminhamentos (por exemplo, indicação para consultórios particulares) (Tabela 3).

Em relação às ações desempenhadas pelo pessoal auxiliar (ACD eTHD) nas ESB, cerca de 50\% faziam visitas domiciliares e reuniões com a comunidade, $82 \%$ realizavam agendamento de pacientes, 70,8\% realizavam ações de prevenção e promoção de saúde, além de tarefas clínicas de auxílio ao cirurgião-dentista como instrumentação $(86,7 \%)$ edesinfecção eesterilização de materiaise instrumentais (89,9\%). Quanto às ações desempenhadas pelos cirurgiões-dentistas, $94,2 \%$ afirmaram realizar atendimentos clínicos, $69,4 \%$, visitas domiciliares, $92,4 \%$, prevenção e promoção da saúde, $63,6 \%$ participavam de reuniões com a ESF, $70,5 \%$, planejamento dos trabalhos, $62,2 \%$, interação com outros setores, $64,7 \%$,reunião com a comunidade da área de abrangência, 26,9\% articulavam ações de referência e contra-referência e apenas $11 \%$ do total utilizaram os dados do SI AB para o planejamento de suas ações (Tabela 5).

Tabela 4. Forma de agendamento dos usuários das ESB no PSF no Estado de MG, em 2004*.

\begin{tabular}{lrr}
\hline \multicolumn{1}{c}{ Forma de agendamento } & N & $\%$ \\
\hline Nas USF pelo ACD & 142 & 51,1 \\
Agente comunitário de saúde (ACS) & 122 & 43,9 \\
Livre demanda & 111 & 39,9 \\
Triagem de risco & 75 & 26,9 \\
Outras formas de agendamento & 36 & 12,9 \\
Nas USF pelo THD & 25 & 09,0 \\
*(respostas múltiplas); N total = 278 & &
\end{tabular}


Tabela 5. Ações desempenhadas pelos componentes das ESB no PSF no Estado de M G, em 2004.

\begin{tabular}{lrc}
\hline \multicolumn{1}{c}{ Ações das ESB no PSF } & N & $\%$ \\
\hline Pessoal auxiliar: ACD e THD & & \\
Desinf. e esterilização de mat. e instrumentais & 250 & 89,9 \\
Instrumentação do CD & 241 & 86,7 \\
Agendamento de pacientes & 228 & 82,0 \\
Prevenção e promoção de saúde & 197 & 70,8 \\
Visitas domiciliares & 139 & 50,0 \\
Reuniões com a comunidade & 139 & 50,0 \\
& & \\
Cirurgião-dentista & & \\
Atendimentos clínicos & 262 & 94,2 \\
Prevenção e promoção de saúde & 257 & 92,4 \\
Planejamento do trabalho & 196 & 70,5 \\
Visitas domiciliares & 193 & 69,4 \\
Reunião com a comunidade da área de & 180 & 64,7 \\
abrangência & & \\
Reunião com toda a equipe de SF & 177 & 63,6 \\
Interação com outros setores & 173 & 62,2 \\
Articulação de referência e contra-referência & 75 & 26,9 \\
Utiliz. dados do SIAB para planejamento & 31 & 11,1 \\
das ações & & \\
\hline * & &
\end{tabular}

$*$ (respostas múltiplas); $\mathrm{N}$ total $=278$

Quanto à integração entre as ESB e as ESF, 212 equipes $(76,2 \%)$ afirmaram que existia integração entreos membros destas equipes. No entanto, $54 \%$ responderam realizar reuniões periódicas (semanais, quinzenais e mensais), en quanto $34,9 \%$ realizavam reuniões esporádicas e $11,2 \%$ nunca as realizavam. Além disso, 69\% (192) responderam que não utilizavam prontuários únicos para as ESB e ESF. Sobre o objetivo das ESB no PSF, 65,8\% (183) dos cirurgiões-dentistas acreditavam que as equipes estavam reorganizando a atenção básica em novas bases e critérios que não apenas a cura das doenças e $34,2 \%$ (95) responderam que as ESB continuavam reproduzindo a clínica particular no serviço público ou estavam voltadas apenas para 0 atendimento de crianças em idade escolar.

\section{Discussão}

A associação estatisticamente significante $(p<0,01)$ entreo portemunicipal ea implantação deESB no PSF demonstra que o porte municipal pode ter influenciado na implantação das ESB no PSF. Este resultado corrobora com os observados no Esta- do do Paraná ${ }^{1}$, onde $92,64 \%$ dos municípios com ESB eram depequeno ou médio porte, enão difere da própria implantação do Programa Saúde da Família no restante do país onde, nos grandes centros urbanos, esta implantação tem se dado de modo mais lento.

Os primeiros anos de sucesso do PSF foram marcados pela sua instalação em municípios de pequeno e médio porte ${ }^{12}$. Segundo $M$ anfredini ${ }^{13}$, alguns argumentos poderiam explicar esta situação, como o fato dos maiores municípios já disporem dealgum tipo derede assistencial, mesmo que de baixa cobertura populacional, sendo que isto talvez tenha sido um fator que não estimulasse a adoção da estratégia da saúde bucal no PSF em municípios maiores ou então a dificuldade de expansão de serviços públicos no período posterior à sanção da Lei de Responsabilidade Fiscal. Além disso, pode-se destacar também que, como a cobertura populacional era o critério para 0 aumento nos valores do repasse dos recursos para a manutenção das equipes de PSF, os municípios menores eram privilegiados, pois com poucas equipes atingiam uma grande cobertura recebendo 0 teto dos recursos. A Portaria $648 / 2006^{14}$ definiu as equipes de PSF em modalidades I ell, com valores fixos para cada modalidade, sendo que os critérios de cobertura populacional não são considerados para o financiamento das equipes:

1. ESF modalidade 1: são as ESF que atendem aos seguintes critérios:

I - estiverem implantadas em municípios com Índice de Desenvolvimento Humano (IDH) igual ou inferior a 0,7 epopulação de até 50 mil habitantes nos Estados da Amazônia Legal e até 30 mil habitantes nos demais estados do país; ou

II - estiverem implantadas em municípios que integraram o Programa de Interiorização do Trabalho em Saúde (PITS) e que não estejam enquadrados no estabelecido na alínea I deste item; e

III - estiverem implantadas em municípios não incluídos no estabelecido nas alíneas I e II e atendam a população remanescente de quilombos ou residente em assentamentos de no mínimo 70 (setenta) pessoas, respeitado o número máximo de equipes por município, publicado em portaria específica.

2. ESF M odalidade 2: são as ESF implantadas em todo o território nacional que não se enquadram nos critérios da modalidade 1.

No caso das ESB, o incentivo sempre foi fixo de acordo com a modalidade, portanto, não sofrendo alterações em relação aos critérios populacionais; porém, estes influenciaram indiretamente, pois o primeiro critério para se implantar as ESB é 
de já se ter implantado Equipes de Saúde da Família (ESF). Dessa forma, pode-se justificar que, na relação entre o número de ESB implantadas por município, incluídos no estudo, no Estado de M inas Gerais, a maior parte $(57,2 \%)$ havia implantado apenas uma equipe, enquanto apenas 13,9\% dos municípios relataram ter implantado mais de três equipes (Tabela 1 ).

O maior incremento de ESB no PSF no Estado de M inas Gerais foi obtido no ano de 2003 (39,8\% das equipes), sendo que estes números coincidem com 0 aumento nos incentivos financeiros às ESB e com a ampliação destas ações por todo território nacional; entre dezembro de 2002 e setembro de 2004 , o número de ESB no PSF cresceu $106,8 \%$ em todo o país ${ }^{4}$. Atualmente, segundo dados do $\mathrm{M} \mathrm{S}^{15}$, existem 15. 215 equipes de saúde bucal atuando em 4.314 municípios do país; de dezembro de 2002 a janeiro de 2007, foram implantadas 10.954 novas ESB na Estratégia de Saúde da Família. Significa dizer que $56,6 \%$ da equipes SF já contam com equipe de saúde bucal, o que representa um aumento de mais de $257 \%$ no número de ESB na SF. São aproximadamente 75 milhões de pessoas cobertas com ações de saúde bucal na Estratégia de Saúde da Família (40,2\% da população brasileira).

A portaria $673 / \mathrm{GM}^{16}$ alterou a relação entreESB e ESF, determinando que pudessem ser implantadas, a critério do gestor municipal, quantas equipes de saúde bucal fossem necessárias, desde que não ultrapassem o número existentede Equipes de Saúde da Família. Através desta medida, a população adscrita sob responsabilidade de cada ESB passou a ser de no máximo quatro mil equinhentos habitantes por equipe. Anteriormente, para cada equipe de saúde bucal a ser implantada, deveriam estar implantadas duas equipes de saúde da família, sen do quea média de população a ser atendida por equipe era 6.900 (seis mil e novecentos) habitantes ${ }^{17}$. No presenteestudo, aproximadamente $76 \%$ dos municípios relataram uma proporção de até quatro mil habitantes por equipe.

Embora a relação entre equipe/habitanteesteja dentro das recomendações, percebem-se nos relatos dos cirurgiões-dentistas que a demanda é excessiva, com predominância das ações curativas, não sobrando tempo para outras atividades: São muitas as ações a serem realizadas por um único cirurgião-dentista que é responsável por um número grande de pessoas.

Além disso, al guns $C D$ s relataram que o município ainda mantém a relação de 1 ESB/2ESF: Somos um dentista para dois PSF. A necessidade curativa não nos permite atender na filosofia de prevenção e promoção.
A alta ocorrência denecessidades curativas pode ser explicada pela dívida assistencial em saúde bucal a que a população foi submetida ao longo da história e pela ausência de programação das ações, fato previsto por Zanetti ${ }^{18}$ sobre os riscos de um aumento rápido do número de ESB sem a devida preparação: [...] a equipe local, desorientada programaticamente, não aguentará o "tranco" da explosão dedemanda reprimida. Assim, ficará em descoberto 0 saldo da dívida assistencial acumulada ao longo da história. Afinal, o trabalho dos ACS nos domićlios reti rará a tampa de uma panela de pressão que cozinha secularmente as populações em fogo brando ${ }^{18}$.

A falta de ações programáticas também pode ser evidenciada na proporção de cirurgiões-dentistas $(48,9 \%)$ que relataram não haver participado denenhum treinamento sobre PSF, ou seja, o cirurgião-dentista não está capacitado a planejar ações de acordo com os objetivos do PSF, reproduzindo a clínica particular no serviço público com uma concepção de prática da odontologia de mercado, centrada na assistência odontológica ao indivíduo doente realizada por um sujeito individual (o CD) no restrito ambiente do consultório ${ }^{19}$, com um trabalho de baixa produção, diferente da situação descrita pelo documento Diretrizes da Política Nacional de Saúde Bucal ${ }^{20}$, que classifica a SB no PSF como um novo espaço de práticas e relações a serem construídas com possibilidades de reorientar o processo de trabalho e a própria inserção da saúde bucal no âmbito dos serviços de saúde. Vislumbra-se uma possibilidade deaumento de cobertura, de efetividade na resposta às demandas da população edealcance de medidas de caráter coletivo ${ }^{20}$.

Além disso, um dos grandes nós críticos dos serviços públicos de saúde - a organização da de manda - exibe fragilidade quando cerca de $74 \%$ das ESB respondentes relataram utilizar mais de uma forma de agendamento dos usuários, ou seja, são várias portas de entrada ao serviço (Tabela 4). A livre demandaémantida em $39,9 \%$ das ESB como opção de organização da demanda: [...] um dos grandes conflitos com os quais hoje se defronta a organização da assistência odontológica é manter a racionalidadee a praticidade do atendimento a grupos priorizados sem, no entanto, comprometer a universalidade e, além disso, manter as características de um sistema eficaz e resolutivo ${ }^{21}$.

As ações programadas de assistência devem levar em conta o risco de adoecimento, seja ele individual ou familiar. A avaliação de risco permite que o serviço de saúde estabeleça como critério para definição de prioridade no atendimento 0 agravo à saúde e/ou grau de sofrimento - individual, familiar, social e não mais a ordem de chega- 
da. Deve ser realizado por profissional da saúde que identifica os usuários que necessitam de atenção priorizada22.

Em relação à priorização, constatou-se um baixo número de $\operatorname{ESB}(26,9 \%)$ utilizando a triagem de risco, que seria uma forma de incorporar aos serviços o princípio da equidade, além do que, mesmo estes, admitem outras opções de organização da demanda, relatando na opção "outras formas de agendamento" que realizavam, por exemplo, consultas nas escolas como forma de agendamento, com evidente priorização do atendimento da população em idade escolar, fato este confirmado por $34,2 \%$ dos cirurgiões-dentistas que afirmaram que as ESB no PSF continuam reproduzindo a clínica particular no serviço público ou estão voltadas apenas ao atendimento de crianças em idade escolar, o que se poderia definir como sendo o "velho travestido de novo" ${ }^{18}$. Apesar das dificuldades em relação à demanda, a universalidade pode ser constatada, pois, em média, 79\% das ESB relataram atender a toda população (todas as faixas etárias).

No presente estudo, pode-se observar que a maior parte das ações são voltadas ao atendimento clínico, mas há a participação em outras atividades (Tabela 5). Na distribuição das tarefas, o M inistério da Saúde recomenda que, para maior resolutividade do serviço, deve-se disponibilizar tempo de consulta suficiente e adequado à complexidade do tratamento e sugere que de $75 \%$ a $85 \%$ da hora clínica do CD seja dedicada à assistência e de $15 \%$ a $25 \%$ para outras atividades, sugerindo cautela no deslocamento frequente deste profissional (CD) para ações col etivas e enfatizan do que as atividades educativas e preventivas em nível coletivo devem ser executadas, preferencialmente, pelo pessoal auxiliar, cabendo ao CD planejá-las, organizá-las, supervisioná-las e avaliá-las ${ }^{20}$.

Outro aspecto fundamental desta estratégia diz respeito ao processo de trabalho. Ao colocar ao setor saúde bucal a proposta de sua inserção em uma equipe multiprofissional, além de introduzir o "novo", afronta valores, lugares e poderes consolidados pelas práticas dos modelos que 0 antecederam. Esta situação traz o desafio de se trabaIhar em equipe ${ }^{20}$. Embora constituindo a equipe detrabal ho de uma Unidade Básica de Saúde, esses profissionais nem sempre estão preparados e com disposição para agir de forma integrada. Saber lidar com esses encontroséum enormedesafio, pois além do potencial de integração, étambém um lugar de conflitos, de resistências e de disputas ${ }^{22}$.

A maior partedos cirurgiões-dentistas (76,2\%) relatou haver integração entre as ESB e ESF no atendimento às famílias; no entanto, esta interação não se manifesta no planejamento e/ou na troca de saberes, pois, das ESB que relataram realizar reuniões periódicas entre todos os componentes do PSF, apenas $27 \%$ as realizavam em curtos espaços de tempo (semanais ou quinzenais), as demais equipes realizavam reuniões mensais, esporádicas ou não as realizavam, sendo que a maior parte das ESB (69\%) não utilizava prontuários únicos com as ESF. Assim, pode-se observar que, embora houvesse um contato entre os profissionais, não se podia classificar este de interdisciplinaridade e/ou multiprofissionalismo. Esta fal ta de interação também pode ser notada nos relato dos CDs: Deveria haver mais ações conjuntas, entre SB eESF. 0 paciente deveria ser tratado como um todo. Todas as ações educativas e preventivas deveriam ser juntas e não segmentadas (sic).

Observa-se, portanto, uma necessidade deevolução na integração entre os vários profissionais do PSF; este distanciamento talvez possa ser explicado por fatores como a inserção tardia das ESB no PSF, pela formação excessivamente individualista e tecnicista dos profissionais de saúde bucal que dificultam a abordagem do indivíduo como um todo e pela demanda excessiva que toma grande parte do tempo das ESB, impedindo-a de interagir com os demais profissionais.

A atuação da equipe de saúde bucal (ESB) não deve selimitar exclusivamenteao campo biológico ou ao trabal ho técnico-odontológico. A equipe deve interagir com profissionais de outras áreas, de forma a ampliar seu conhecimento, permitindo a abordagem do indivíduo como um todo. A troca de saberes e o respeito mútuo às diferentes percepções devem acontecer permanentemente entre todos os profissionais de saúde para possibilitar que aspectos da saúde bucal também sejam devidamente apropriados e se tornem objetos das suas práticas. A ESB deveser - esesentir - parte da equipe multiprofissional em unidades de saúde de qualquer nível de atenção ${ }^{20}$. No trabalho em equipe, ninguém perde seu núcleo de atuação profissional específica, porém, a abordagem dos problemas é que assume uma nova dimensão. Conhecer, compreender, tratar e controlar passa a ser uma responsabilidade compartilhada22.

A precarização das relações detrabalho dos profissionais das ESF éum dos grandes problemas ainda enfrentados no desdobramento desta estratégia. Segundo o M S23, a seleção dos profissionais para as ESF deveria ser por testeseletivo interno, concurso público ou por recrutamento externo através de contratação em regime de CLT (consolidação das leis trabal histas). No entanto, os resultados deste 
trabalho (Tabela 1) demonstram que, no Estado de Minas Gerais, apenas 33\% relataram vínculos estáveis (teste sel etivo interno e concurso externo); as demais equipes (67\%) relataram outras formas de contratação, como credenciamento, indicação política, nomeação, licitação, terceirização, contratos por cooperativas, contrato temporário, contrato de prestação de serviços, etc. Este resultado é semelhante ao encontrado em pesquisa realizada pelo Núcleo de Pesquisa em Saúde Coletiva (NESCON/UFM G) juntamente com a Coordenação Geral da Política de Recursos Humanos do MS, em que, em níveisnacionais, 70,9\% doscirurgiões-dentistas foram contratados por vínculos temporários ou prestação de serviços, sendo que na Região Sudeste este tipo de contratação é relatada em $56,4 \%$ dos $\operatorname{casos}^{24}$. Estes tipos de vínculos, além de não resguardar os direitos trabal histas dos profissionais, fazem com que estes fiquem a mercê das mudanças políticas, fato observado nos relatos dos cirurgiões-dentistas: Estou neste sistema há cinco anos e não tenho férias, $1 / 3$ de férias e nem 130 salário. Por questões políticas, este trabalho deverá ser alterado. 0 prefeito eleito acabará com esta equipe, acho difícil os profissionais das ESB poderem fazer um trabalho contínuo e decisivo estando sempre ameaçados por questões políticas (sic).

Além disso, dos dezoito municípiosqueinformaram não estar em condições de responder à pesquisa, quinze relataram motivos políticos como demissão de secretários de saúde, de coordenadores de saúde bucal ou dissolução de equipes. Aparentemente, estefato se repetiu por todo país, pois o M S encaminhou aos municípios um documento (aviso-circular no 013/GM de 28/10/04), assinado pelo M inistro da Saúde, informando sobre uma onda de denúncias sobre demissões "políticas" póseleições de 2004 do PACS/PSF/SB, esclarecendo que seriam realizadas auditorias pelo DENASUS (Departamento Nacional de Auditoria do SUS) e, se comprovadas as denúncias, os repasses do M S seriam suspensos, o que se configuraria em uma medida de peso. Contudo, esta apresentou-se paliativa, não atingindo a raiz e não resolvendo 0 problema.

Um segundo fato relativo aos recursos humanos é a questão salarial (Tabela 2). $93 \%$ das ESB tinham jornada de trabalho de oito horas diárias, conforme as diretrizes do PSF e, para tanto, 72,3\% dos cirurgiões-dentistas recebiam salário mensal entre $R \$ 1.200,00$ e $R \$ 2.200,00$ (média de $R \$$ $1.700,00)$. Este dado é também semelhante ao encontrado pelo $\mathrm{MS}^{24}$, o qual registrou um salário médio nacional do $C D$ de $R \$ 1.576,00$, enquanto que para a Região Sudestea média salarial era de R \$ $1.813,00^{24}$. Assim, observou-se uma discrepância enorme entre os salários dos cirurgiões-dentistas e dos médicos cuja média salarial nacional era de $\mathrm{R} \$$ $4.980,00$ e para a Região Sudeste, de $R \$ 4.120,00^{24}$. Diferenças salariais pronunciadas podem constituir fator desencadeante de conflitos nas ESF ${ }^{25}$.

0 discurso mais frequente descrito por cirurgiões-dentistas, coordenadores e até secretários de saúde é com relação aos recursos, seja quanto à baixa remuneração dos profissionais, falta de materiais para prevenção e promoção da saúde ou falta de estrutura física, embora tenha havido um aumento considerável nos incentivos das ESB - na modalidadeI, $R \$ 20.400,00$ e na modalidade II, $R \$$ $26.600,00^{26}$ - , todos entendem que o MS deveria repassar mais recursos, como vemos no depoimento de um coordenador: 0 teto financeiro da odontologia não cobre todos os procedimentos realizados, o dentista trabalha quarenta horas semanais e não são pagos todos os procedimentos ao município.

Não há, portanto, a compreensão de que 0 município é responsável pelos serviços e co-responsável pelo financiamento, devendo complementar o incentivo do governo federal.

O PSF, ao priorizar a atenção básica, não faz uma opção econômica pelo mais barato, nem técnica pela simplificação, nem política por qualquer forma de exclusão. O PSF deveestar articulado com os demais níveis de atenção e conhecendo a sua população, com suas necessidades, tem a possibilidade de ordenar os encaminhamentos, racionalizando o uso dos recursos terapêuticos mais caros. Portanto, as ESF, estando inseridas na atenção básica, no primeiro nível de ações, devem articular a referência e contra-referência dos serviços de saú$\mathrm{de}^{27}$. Sobre os encaminhamentos dos casos de maior complexidade ( Tabela 3), observa-se que apenas $28 \%$ dos casos têm um encaminhamento favorável, sendo resolvidosem unidades especializadas no próprio município, a maior parte é encaminhada para municípios vizinhos. Nos casos que foram relatados como resolvidos na própria USF $(6,1 \%)$, geralmente a solução é mutiladora, pois normalmentea unidadenão dispõedetecnologia suficiente para tratamentos especializados, resolvendo estes casos com a remoção do elemento que necessita de tratamento. Os outros encaminhamentos relatados são, em sua maioria, indicações para serviços particulares. Portanto, a integralidade da atenção em saúdebucal fica prejudicada com a grandemaioria dos casos sem encaminhamentos resolutivos. 


\section{Consideraçõesfinais}

Observa-se uma evolução quantitativa das ESB, possibilitando um maior acesso aosserviços de saúde bucal; todavia, diferenças e dificuldades estão presentes em virtude das dimensões do estado e do aspecto político em que a estratégia está inserida.

Quanto aos aspectos analisados (operacionais e administrativos), identifica-se como pontos positivos nas ESB a observação do princípio da universalidade, a jornada de trabalho de oito horas e a ampliação quantitativa. Como pontos negativos, destaca-se a falta de capacitação das ESB, a demanda excessiva, a precarização das relações de trabalho com baixos salários e contratações instáveis e a falta de envolvimento entre ESB e ESF. Além disso, os resultados apresentados demonstram que várias questões exigiriam estudos específicos eaprofundados que pudesse instrumentalizar esta estratégia.

\section{Colaboradores}

EC Lourenço, AC Pereira, ACB Silva e MC Meneghin participaram igualmente de todas as etapas de desenvolvimento do estudo.

\section{Agradecimentos}

À Profạ. Márcia Helena Baldani (UEPG), à Profạ Gláucia M aria Bovi Ambrosano (FOPU NICAM P) e ao Departamento de Saúde Bucal da Secretaria de Estado da Saúde de M inas Gerais.

\section{Referências}

1. Baldani MH, Fadel CB, Possamai T, Queiroz MGS. A inclusão da odontologia no Programa Saúde da Família no Estado do Paraná, Brasil. Cad Saude Publica 2005; 21(4):1026-1035.

2. Brasil. Ministério da Saúde. Secretaria executiva. Programa Saúde da Família - PSF. Brasília: Ministério da Saúde; 2001.

3. Brasil. M inistério da Saúde. Secretaria executiva. Programa Saúde da Família: Equipes de Saúde Bucal. Brasília: Ministério da Saúde; 2002.

4. Brasil. M inistério da Saúde. Coordenação de saúde bucal. Manual do programa Brasil sorridente. [acessado 2005 abr 4]. Disponível em: http://portal.saude.gov.br/ portal/saude/area.cfm?id_area $=406$

5. Silveira Filho AD. A Saúde Bucal no PSF: o desafio de mudar a prática. [acessado 2003 dez 20]. Disponível em: htpp://www.saude.gov.Br/bucal

6. Narvai PC. Saúde bucal no PSF. SUS ou SUSF? Jornal do Site O donto [periódico na Internet]. 2001 [acessado 2003 out 20]; 3(37). Disponível em: http://www.jornal dosite.com.br/arquivo/anteriores/capel/capel8. htm

7. Sousa MF, organizadora. Os sinais vermelhos do PSF. São Paulo: Hucitec; 2002.

8. Medina MG, Aquino R. Avaliando o Programa de Saúde da Família. In: Sousa M F, organizadora. Os sinais vermelhos do PSF. São Paulo: Hucitec; 2002.

9. M inas Gerais. Secretaria de Estado da Saúde. Diretoria de ações básicas. Programa saúde da família: Estratégias de atenção básica e programa de agentes comunitários. [acessado 2004 dez 14]. Disponível em: http://www. saude.mg.gov.br:8180/saude/viewController.jsp? page $=43$ 
10. Calado GS. A Inserção da Equipe de Saúde Bucal no Programa de Saúde da Família: principais avanços e desafios [dissertação]. Rio de Janeiro (RJ): Escola Nacional de Saúde Pública, Fundação Oswaldo Cruz; 2002.

11. Goulart FAA. Experiências em saúde da família: cada caso é um caso [tese]. Rio de Janeiro (RJ): Escola Nacional de Saúde Pública, Fundação Oswaldo Cruz; 2002.

12. Alves Sobrinho EJM, Souza MF. O PSF nos grandes municípios: São Paulo, um investimento à parte! In: Sousa M F, organizadora. Os sinais vermelhos do PSF. São Paulo: Hucitec; 2002.

13. Manfredini MA. Saúde Bucal no Programa Saúde da Família no Brasil. In: Dias AA, organizador. Saúde Bucal Coletiva: metodologia de trabalho e práticas. São Paulo: Santos; 2006. p.43-73.

14. Brasil. M inistério da Saúde. Portaria no 648, de 28 de março de 2006. Aprova a Política Nacional de Atenção Básica. Diário Oficial da União 2006; 29 mar.

15. Brasil. Secretaria de atenção à saúde. Departamento da atenção básica. Informe da atenção básica 2007; 8.

16. Brasil. Ministério da Saúde. Portaria no 673, de 03 de junho de 2003. Atualiza e revê o incentivo financeiro às Ações de Saúde Bucal: portaria de normas e diretrizes da saúde bucal. Diário Oficial da U nião 2003; 4 jun.

17. Brasil. M inistério da Saúde. Portaria ํㅡ 1.444, de 28 de dezembro de 2000. Estabelece incentivo financeiro para a reorganização da atenção à saúde bucal prestada nos municípios por meio do Programa de Saúde da Família. Diário Oficial da União 2000; 29 dez.

18. Zanetti CHG. Por um caminho sustentável para universalização da atenção básica: Saúde Bucal da Família com equidade e integralidade. [acessado 2003 fev 8]. Disponível em: htpp://www.saudebucalcoletiva.unb.br

19. Narvai PC. O dontologia e saúde bucal coletiva. $2^{\underline{a}}$ ed. São Paulo: Santos; 2002.
20. Brasil. Ministério da Saúde. Coordenação de saúde bucal. Diretrizes da política nacional de saúde bucal. Brasília: M inistério da Saúde; 2004.

21. Roncalli AG. A organização da demanda em serviços públicos de saúde bucal: universalidade, equidade e integralidade em saúde bucal coletiva [tese]. Araçatuba (SP): Universidade Estadual Paulista, Faculdade de Odontologia de Araçatuba; 2000.

22. Brasil. M inistério da Saúde. Cadernos da atenção básica no 17: Saúde Bucal. Brasília: M inistério da Saúde; 2006.

23. Brasil. M inistério da Saúde. Guia prático do Programa Saúde da Família. Brasília: M inistério da Saúde; 2001.

24. Brasil. M inistério da Saúde. Observatório de Recursos H umanos em Saúde no Brasil: estudos e análises. In: Barros AFR, Santana JP, Santos N eto PM, organizadores. Brasília: Ministério da Saúde; 2004.

25. M achado MH. Programa saúde da família no Brasil algumas considerações sobre o perfil dos médicos e enfermeiros. In: Sousa M F, organizadora. Os sinais vermelhos do PSF. São Paulo: Hucitec; 2002.

26. Brasil. Ministério da Saúde. Portaria no 74, de 20 de janeiro de 2004. Reajusta os valores dos incentivos financeiros às Ações de Saúde Bucal: portaria de normas e diretrizes da saúde bucal. Diário Oficial da União 2003; 21 jan.

27. Brasil. Departamento da atenção básica. Secretaria de políticas de saúde. Informes técnicos institucionais: programa saúde da família. Rev. Saude Publica 2002; 34(3):316-319.

Artigo apresentado em 15/01/2007

Aprovado em 10/12/2007

Versão final apresentada em 10/01/2008 